\title{
EFFECTIVENESS OF VIDEO ASSISTED TEACHING PROGRAM ON PREVENTION OF ORAL CANCER AMONG TOBACCO CHEWERS IN SELECTED VILLAGE OF RUPANDEHI, NEPAL
}

Astha Sharma Pokharel, ${ }^{1}$ Ikshaya Rana, ${ }^{1}$ Pragya Shrestha, ${ }^{1}$ Neelam Shrestha ${ }^{1}$

\begin{abstract}
\section{INTRODUCTION}

Cancer is defined as the uncontrollable growth of cells that invade and cause damage to surrounding tissue. Oral diseases and conditions share modifiable risk factors with the leading NCDs (Cardiovascular diseases, cancer, chronic respiratory diseases and diabetes). This study was carried out to assess the knowledge regarding prevention of oral cancer and to find out the effectiveness of video assisted teaching program among tobacco chewers.
\end{abstract}

\section{MATERIAL AND METHODS}

A pre-experimental one group pre-test post-test design study was conducted to find the effectiveness of video assisted teaching for prevention of oral cancer among tobacco chewers in Dhakdahi village of Rohini rural municipality of Rupandehi District, Nepal. The total duration of the study was three months 5/5/2019 to 26/8/2019. The study samples tobacco chewers were selected by non-probability convenient sampling. Self-administered structured questionnaire was used for socio-demographic variables and video in local language for prevention of oral cancer was used as a intervention for the study group and collected data was analysed by using descriptive and inferential statistics with SPSS software version 20.0

\section{RESULTS}

The findings of the study show that the mean score pre-test knowledge was 7.23 and standard deviation 1.801. After the intervention, the mean score of post-test knowledge was 9.96 and standard deviation 1.56. No significant association was found between socio-demographic variables and post-test knowledge level.

\section{CONCLUSION}

Based on the study findings, the knowledge level on prevention of cancer is inadequate before intervention of video assisted teaching and after the video assisted teaching the knowledge on prevention was found to be improved. There was overall gain in the knowledge score teaching program following the video assisted teaching program.

KEYWORDS Knowledge, Oral cancer, Tobacco chewers.

1. Universal College of Nursing sciences, Bhairahawa, Nepal

DOI: http//doi.org/10.3126/jucms.v8i02.34094

For Correspondence

Ms. Astha Sharma Pokharel

Universal College of Nursing Sciences

Bhairahawa

Email: asthasis73@gmail.com 


\section{INTRODUCTION}

Oral health is a key indicator of overall health, well-being and quality of life. It encompasses a range of diseases and conditions that include dental caries, periodontal disease, tooth loss, oral cancer, oral manifestations of HIV infection, oro-dental trauma, noma and birth defects such as cleft lip and palate. The global burden of disease study (2017) estimated that oral diseases affect 3.5 billion people worldwide, with untreated dental caries being among the most prevalent noncommunicable diseases. According to the International agency for research on cancer, the incidence of oral cancer was within the top three of all cancers in some Asian-Pacific countries in $2018 .{ }^{1}$

Most oral diseases and conditions share modifiable risk factors with the leading NCDs (Cardiovascular diseases, cancer, chronic respiratory diseases and diabetes). These risk factors include tobacco use, alcohol consumption and unhealthy diets high in free sugars, all of which are increasing at the global level. There is a proven relationship between oral and general health. It is reported, for example, that diabetes mellitus is linked with the development and progression of periodontitis. Moreover, there is a causal link between high sugar consumption and diabetes, obesity and dental caries. ${ }^{2}$

Oral cancer includes cancers of lip and all subsites of the oral cavity, and oropharynx. The age-adjusted incidence of oral cancer (Cancers of the lip and oral cavity) in the world is estimated at four cases per 100,000 people. However, there is wide variation across the globe, from no recorded cases to around 20 cases per 100,000 people. Oral cancer is more common in men, in older people, and varies strongly by socioeconomic condition. In some Asian-Pacific countries, the incidence of oral cancer ranks among the three top cancers. Tobacco, alcohol and areca nut (betel quid) use are among the leading causes of oral cancer. In regions like North America and Europe, "high risk" human papillomavirus infections are responsible for a growing percentage of oro-pharyngeal cancers among young people.

Cancer is the second leading cause of death globally, and is responsible for an estimated 9.6 million deaths in 2018 . Globally, about one in six deaths is due to cancer. Approximately $70 \%$ of deaths from cancer occur in low- and middle-income countries. Around one-third of deaths from cancer are due to the five leading behavioural and dietary risks: high body mass index, low fruit and vegetable intake, lack of physical activity, tobacco use, and alcohol use. Tobacco use is the most important risk factor for cancer and is responsible for approximately $22 \%$ of cancer deaths. Latestage presentation and inaccessible diagnosis and treatment are common. Tobacco use, alcohol use, unhealthy diet, and physical inactivity are major cancer risk factors worldwide and are also the four shared risk factors for other noncommunicable diseases. ${ }^{4}$

The aim of this study was to assess existing knowledge through pre-test, to administer video assisted teaching, to compare pre-test and post-test knowledge scores.

\section{MATERIAL AND METHODS}

A pre-experimental design was used for the study. The subjects were selected by using probability convenient sampling technique from residents of selected area of Rupandehi District, Nepal. The total subjects under the study were 80 community people. The data was collected by using informational video to assess knowledge level of community people among tobacco chewers on prevention of oral cancer. The post-test was done after one week of pre-test. The people who refused to participate were excluded. The total duration of the study was three months 5/5/2019 to 26/8/2019. Permission was obtained from institutional research committee of UCMS-TH. Researcher herself collected the data and on an average 60 minutes were given to complete the tool and administered structured questionnaire. Descriptive and inferential statistics were used to analyse the data of the study. The statistical data was analysed by using SPSS 20.0.

\section{RESULTS}

Regarding socio-demographic variables, $57 \%$ of the respondents were between the age of 40-59 years. Eighty percent were literate. Eighty percent lived in joint family. Forty three percentage were farmers by occupation. Seventy six percentage of respondents were non-vegetarians by diet.

Table 1. Sociodemographic characteristic $(\mathbf{n}=\mathbf{8 0})$

\begin{tabular}{lcc}
\hline Characteristics & Frequency & Percentage \\
\hline Age & 23 & 28.7 \\
$20-39$ & 57 & 71.2 \\
$40-59$ & & \\
Sex & 52 & 65 \\
Male & 28 & 35 \\
Female & & \\
Marital Status & 8 & 10 \\
Unmarried & 72 & 90 \\
Married & & \\
Number of children & 23 & 28.7 \\
One & 49 & 61.2 \\
More than one & 8 & 10 \\
None & & \\
Type of family & 16 & 20.0 \\
Nuclear & 64 & 80.0 \\
Joint & & \\
Education & 16 & 20.0 \\
Illiterate & 36 & 45.0 \\
Primary level & 22 & 27.5 \\
Higher secondary level & 6 & 7.5 \\
Graduate and above & & \\
Occupation & 24 & 30.0 \\
Business & 35 & 43.8 \\
Farmer & 13 & 16.3 \\
Service & & 10.0 \\
Student & & \\
\hline & & \\
\hline & &
\end{tabular}




\begin{tabular}{lcc}
\hline Characteristics & Frequency & Percentage \\
\hline Monthly Income & 1 & 1.3 \\
Below 10000 & 29 & 36.3 \\
10000-20000 & 46 & 57.5 \\
20000-30000 & 4 & 5.0 \\
Above 30000 & & \\
Dietary pattern & 4 & 5.0 \\
Vegetarian & 76 & 95.0 \\
Non-vegetarian & & \\
Habits & 11 & 13.8 \\
Alcohol consumption & 47 & 58.8 \\
Betel chewing & 22 & 27.5 \\
Smoking & & \\
Hobbies & 11 & 13.8 \\
Watching movies & 7 & 8.8 \\
Listening music & 3 & 3.8 \\
Reading books & 59 & 73.8 \\
Chatting & & \\
Source of information & 38 & 47.5 \\
Mass media & 32 & 40.0 \\
Friends & 10 & 12.5 \\
family members/relatives & & \\
Exposure to radiation & 57 & 71.3 \\
Yes & 23 & 28.8 \\
No & & \\
\hline
\end{tabular}

Table 2. Distribution of samples according to level of knowledge before and after intervention $(n=80)$

\begin{tabular}{lcccc}
\hline Level of knowledge & \multicolumn{2}{c}{ Before intervention } & \multicolumn{2}{c}{ After Intervention } \\
& Frequency & Percentage & Frequency & Percentage \\
\hline Inadequate (Below 8) & 52 & $65 \%$ & 4 & $5 \%$ \\
Adequate (Above 8) & 28 & $35 \%$ & 76 & $95 \%$ \\
\hline
\end{tabular}

The above Table 2 shows that pre-test among the subjects, 52 $(65 \%)$ were inadequate level of knowledge, and $28(35 \%)$ of them having an adequate level of knowledge regarding the prevention of oral cancer. In post-test among the subjects, 4 $(5 \%)$ were inadequate level of knowledge and 76 (95\%) had an adequate level of knowledge regarding the prevention of oral cancer.

Table 3. Mean pre-test and post-test knowledge level $(\mathbf{n}=\mathbf{8 0})$

\begin{tabular}{lccc}
\hline Level of knowledge & Mean & Standard deviation* & $\mathrm{t}$-value \\
\hline Before intervention & 7.23 & 1.801 & 16.060 \\
After intervention & 9.96 & 1.56 & \\
\hline
\end{tabular}

*Significant at 0.05 levels

The mean score on level of knowledge regarding prevention of oral cancer was 7.23 and standard deviation 1.801 before intervention. The mean score of level of knowledge after intervention is 9.96. The difference of mean score is 2.73 which is higher than pre- test. The computed value of ' $t$ ' is 16.060 is more than the Table value (1.6644) at $\mathrm{df}(79)$ which is statistically significant at 0.05 levels. This data shows that video assisted teaching was effective in improving the knowledge regarding oral cancer.

\section{DISCUSSION}

Oral cancer is one of the most common malignancies among betel nut chewers in South and South-East Asian countries. Although education for the cessation of the betel nut chewing habit is important, there are no adequate strategies and policies for primary prevention, health promotion and education related to oral cancer in rural areas. There are several risk factors associated with oral cancers. Understanding these factors can help in preventing its onset. Most oral cancers can be related to the excessive use of tobacco and or alcohol. One of the prominent factors to be considered is the age ( 40 years). Most people don't connect their mouths to the rest of their body. ${ }^{5}$ Research shows that tooth decay (cavities) and periodontal (gum) disease may contribute too many serious health conditions. With mounting scientific evidence, the connection between oral infections and other diseases in the body is becoming widely understood and accepted. Gum disease and cavities are chronic, contagious oral infections that can lead to major health concerns and negatively affect the course of other diseases and treatments. Prevention is considered key to maintaining overall health. Proper oral care and regular professional scaling (cleaning) by a dental hygienist are important for keeping the mouth and body healthy. ${ }^{6}$

An effective community prevention program is a planned procedure that prevents the onset of a disease among a group of individuals. The study result shows that in pre-test most of the clients have an inadequate knowledge regarding prevention of oral cancer because the samples belongs to rural based setup, lack of awareness regarding oral cancer. ${ }^{7,8}$ This also may be the reason for the inadequate level of knowledge. This is shown by evident that lack of knowledge regarding the prevention of oral cancer. ${ }^{9}$

A study on public awareness of oral cancer, of oral potentially malignant disorders and of their risk factors in some rural population in Sri Lanka, the study was to investigate the level of public awareness of oral cancer, oral potentially malignant disorders and risk factors for developing these diseases in a province of Sri Lanka, a country with one of the highest incidences of these diseases in the world. The study concluded that, knowledge of oral cancer, oral potentially malignant disorders and their associated risk factors was poor among this population, indicated an urgent need to implement public health education and promotion strategies. ${ }^{10,11}$ In this study, after the intervention, all the samples were improved in level of knowledge. Most of the subjects adopted the positive attitude towards the prevention of oral cancer. The researcher observed that most of the samples responded to the questions very eagerly.

There was no significant association between post-test knowledge and demographic variables such as age, sex, religion, residence, marital status, no of children, type of 
family, occupation, monthly income, diet, recreation, family history of cancer and exposure to radiation.

\section{CONCLUSION}

The following conclusions are made based on the above findings that, at pre-test, most of the subjects have inadequate level of knowledge regarding the prevention of oral cancer. After assessing the post-test level of knowledge, the intervention is proven effective. The study encouraged all the subjects in improving knowledge regarding the prevention of oral cancer. Video assisted teaching showed an effect in improving the level of knowledge regarding the prevention of oral cancer. The video assisted teaching was beneficial in improving in knowledge of community people among tobacco chewers on prevention of oral cancer.

\section{ACKNOWLEDGEMENT}

Researcher would like to thank all the community people of the Dhakdahi village of Rohini rural municipality of Rupandehi who participated in this study.

\section{REFERENCES}

1. Petersen PE. The World Oral Health Report 2003: Continuous improvement of oral health in the 21st centurythe approach of the WHO Global Oral Health Programme. Community Dentistry and Oral Epidemiology. 2003 Dec;31:3-24.

2. Ferlay J, Ervik M, Lam F, Colombet M, Mery L, Piñeros M, Znaor A, Soerjomataram I, Bray F. Global Cancer Observatory: Cancer Today. Lyon: International Agency for Research on Cancer; 2018.

3. GBD 2015 Risk Factors Collaborators. Global, regional, and national comparative risk assessment of 79 behavioural, environmental and occupational, and metabolic risks or clusters of risks, 1990-2015: A systematic analysis for the global burden of disease study 2015. Lancet. 2016 Oct 8;388(10053):1659724.

4. Yang BH, Parkin DM, Cai L, Zhang ZF. Cancer burden and trends in the Asian Pacific Rim region. Asian Pacific Journal of Cancer Prev. 2004 Apr-Jun;5(2):96-117.

5. Amarasinghe HK, Usgodaarachchi US, Johnson NW, Lalloo R, Warnakulasuriya S. Betel-quid chewing with or without tobacco is a major risk factor for oral potentially malignant disorders in Sri Lanka: A case-control study. Oral Oncology. 2010 Apr 1;46(4):297-301.

6. Nakre PD, Harikiran AG. Effectiveness of oral health education programs: A systematic review. J Int Soc Prev Community Dent. 2013 Jul;3(2):103-15.

7. Petersen PE, Aleksejuniene J, Christensen LB, Eriksen HM, Kalo I. Oral health behavior and attitudes of adults in Lithuania. Acta Odontologica Scandinavica. 2000 Jan 1;58(6):243-8.
8. Ju HJ, Oh HW, Kim JY, Lee HS. A cross-sectional study on oral health literacy and its influencing factors among adults: I. Verbal oral health literacy. Journal of Korean Academy of Oral Health. 2012 Jun 1;36(2):97-105.

9. Lee KH, Choi YY, Jung ES. Effectiveness of an oral health education programme for older adults using a workbook. Gerodontology. 2020 Dec;37(4):374-382.

10. Riley III JL, Gilbert GH, Heft MW. Dental attitudes: Proximal basis for oral health disparities in adults. Community Dentistry and Oral epidemiology. 2006 Aug;34(4):289-98.

11. Werner H, Hakeberg M, Dahlström L, Eriksson M, Sjögren P, Strandell A, Svanberg T, Svensson L, Wide Boman U. Psychological interventions for poor oral health: A systematic review. Journal of Dental Research. 2016 May;95(5):506-14. 